\title{
Diastereoselective Catalytic C-H Amination
}

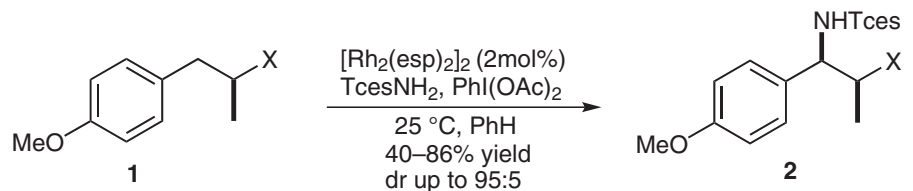

Metal-Catalyzed

Asymmetric

Synthesis and

Stereoselective

Reactions

\section{Key words}

C-H activation

amination

rhodium
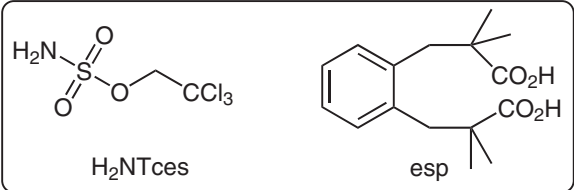

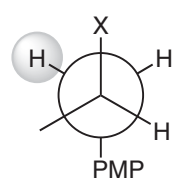

A

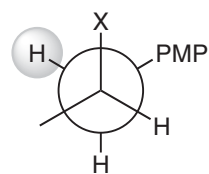

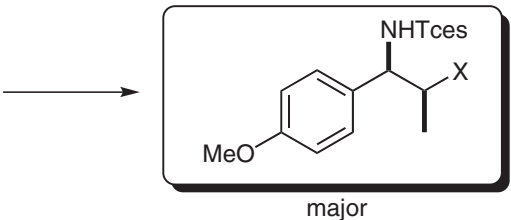

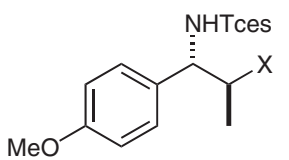

Significance: The metal-mediated direct amination through $\mathrm{C}-\mathrm{H}$ bond insertion is a very powerful transformation. It usually requires a metal nitrene species which undergoes $\mathrm{C}-\mathrm{H}$ insertion into the most nucleophilic $\mathrm{C}-\mathrm{H}$ bond. Herein, the authors report their preliminary results of a diastereoselective version of this reaction applied to acyclic substrates of type $\mathbf{1}$, proceeding with an excellent degree of selectivity and high yields.
Comment: The authors found that especially substrates with bigger substituents $\left[X=\mathrm{PO}(\mathrm{OEt})_{2}\right.$, $\mathrm{SO}_{2} \mathrm{Ph}$ gave the best selectivities. An important feature is that the $\mathrm{C}-\mathrm{H}$ amination process does not affect the configuration of the stereogenic center in $\beta$-position when the reaction was carried out with enantiomerically pure starting material. Furthermore, a possible explanation for the diastereoselective outcome of the transformation has been assumed by considering the staggered conformer $\mathbf{A}$ to be more favored than conformer $\mathbf{B}$ due to dipole repulsion. 